\title{
Study on Comparative Analysis of Polymerization of Pyrrole Using Electrochemical Method and UV Photo Irradiation
}

\author{
Dr. Hemant K. Chitte ${ }^{1}$, Dr. Shraddha M. Bhome ${ }^{2}$ \\ ${ }^{1}$ Department of Physics, Satish Pradhan Dnyanasadhana Collage, Thane, India \\ ${ }^{2}$ Department of Accounting and Finance, Satish Pradhan Dnyanasadhana Collage, Thane, India
}

\begin{abstract}
Polymerization of pyrrole using various methods like pyrrole using electrochemical method and UV Photo irradiation has been investigated. Fourier transform infrared spectroscopy (FTIR), Scanning electron microscopy (SEM), X-ray diffraction (XRD) techniques were used to study the internal structure, material morphology, chemical nature of conducting polymers. The temperature dependence of the electrical conductivity of the Polypyrrole, Their behavior resemble the metallic conductors.
\end{abstract}

KEYWORDS: Conducting Polymers, Electrical Conductivity, FTIR, Oxidants, SEM, UV Photo-irradiation.

\section{INTRODUCTION}

The past few decades have witnessed tremendous advances in the development of organic conductive molecular and polymeric materials and this field continues to be of great scientific and commercial interest. This field of science flourished after discovering new $\pi$-conjugated materials and by tailoring their electrical conductivity from semi-conductive to metallic to a superconductive regime when doped. Polymeric systems with special properties are a field of increasing scientific and technical interest, offering the opportunity to polymer and synthetic organic chemists to synthesize a broad variety of promising new materials, with a wide range of electrical and magnetic properties. Technological use depends crucially on the macromolecules via a simple methodology of organic synthesis. Polypyrrole is one of such polymers whose synthesis does not require any special equipment or much precaution.[1-3]

\section{Importance of different polymerization techniques:}

The pyrrole can be synthesized by many methods. Each method has its own merits and demerits. One of the techniques is electrochemical polymerization which was discussed in detail and in this paper, one more technique Photoinitiated (UV) polymerization will be discussed.

Electrochemical Polymerization: Electrochemical polymerization is the most convenient method to deposit conducting polymer films. The thickness of the film can be controlled by the total charge passed through the electrochemical cell during the film growing process. Moreover, the film can be deposited on patterned microelectrodes [4]. The deposition was carried out on a conducting substrate. However, if the insulating gap between the neighboring electrodes is close enough ( several tens of micrometers), the growing film can cover the insulated gap and connect the electrodes [5]. This is important in fabricating chemiresistors. Various solvents were used for the deposition of Ppy for electrochemical polymerization (e.g. acetonitrile, water, etc.). From the point of view of Nanostructuring of this polymer, it is very important that Ppy synthesis might be performed from water solution at neutral $\mathrm{pH}$ since it opens the ways for entrapment and/or doping of Polypyrrole by various dopants like $\mathrm{NSA}^{\mathrm{p}} \mathrm{p}-\mathrm{TS}$, and $\mathrm{LiClO}_{4}$. Electrochemically synthesized Ppy shows some attractive features such as very good conductivity and high adherence. A potential problem is the local production of a great number of protons in the course of the polymerization which may affect the properties of the Ppy film. [6]

UV Photo irradiation Polymerization: UV-induced radical polymerization has a unique advantage over all other methods [1]. Chemically Polypyrrole can be synthesized in various ways: by oxidative synthesis under "harsh" oxidative conditions, by oxidative synthesis under relatively "mild" conditions where redox enzymes are applied [2], and by oxidative synthesis at ionic-liquid/air interface [3]. The majority of currently used Ppy formation methods use strong oxidants (e.g., $\mathrm{FeCl}_{3}, \mathrm{KMnO}_{4}, \mathrm{~K}_{2} \mathrm{Cr}_{2} \mathrm{O}_{7}$, etc.). In this type of synthesis, the Ppy is doped with the ions of oxidant, products, and/or other materials that are added into the solution used for polymerization. For this reason, biomedical application of such Ppy particles might be problematic due to traces of toxic materials present in the formed polymer, which become entrapped during polymerization. These methods are based on oxidative synthesis 


\section{International Journal of Current Science Research and Review}

ISSN: 2581-8341

Volume 04 Issue 07 July 2021

DOI: 10.47191/ijcsrr/V4-i7-07, Impact Factor: 5.825

under mild conditions where hydrogen peroxide like the oxidants, carries out polymerization of the corresponding conducting polymer. Alternatively, the formation of Ppy particles of different sizes is possible by the variation of the duration of the polymerization reaction [4]. Such Ppy particles, as well as particles of other conducting polymers, have attracted considerable attention within recent years because of their potential applications in various areas, such as drug delivery [5], electrochemical sensors [6], Many mentioned applications need very pure Ppy, which is not usually achieved when oxidants used in the synthesis (e.g., $\mathrm{FeCl}_{3}, \mathrm{KMnO}_{4}, \mathrm{~K}_{2} \mathrm{Cr}_{2} \mathrm{O}_{7}$, etc.) remain entrapped within formed Ppy structures. Iron, although not a toxic metal, still present danger for the cellular environment due to the same radical reactions, as it may use for the initiation of polymerization. On the other hand, entrapped $\mathrm{Fe}^{3+}$ and $\mathrm{Fe}^{2+}$ ions significantly reduce the photostability of formed Ppy. To solve the mentioned problems and to prepare pure Ppy, the $\mathrm{H}_{2} \mathrm{O}_{2}$ could be a very suitable oxidant for the synthesis of Ppy. The $\mathrm{H}_{2} \mathrm{O}_{2}$ can be easily removed from the formed polymer since it is not charged and does not form any ionic interactions within a highly ionized Ppy matrix, as is the case with ionic oxidants. Moreover, the unreacted $\mathrm{H}_{2} \mathrm{O}_{2}$ degrades relatively quickly to $\mathrm{H}_{2} \mathrm{O}$ and $\mathrm{O}_{2}$.

Very little research work was done where $\mathrm{H}_{2} \mathrm{O}_{2}$ was used for the synthesis of Ppy particles. The aim of the present study is the preparation of Ppy by oxidative $\mathrm{H}_{2} \mathrm{O}_{2}$, a very simple, environment-friendly, single-step oxidative polymerization route to prepare Polypyrrole (Ppy) of fixed size and morphology was developed and investigated. The herein proposed method is based on the application of hydrogen peroxide as a weak oxidant as the polymerization initiator. The polymerization reaction is performed on a $5 \mathrm{hr}$ time scale under standard conditions. Alternatively, the formation of Ppy particles of different sizes is possible by the variation of the duration of the polymerization reaction and varying the monomer to oxidant ratio.

\section{METHODOLOGY}

\section{Preparation of Ppy doped films by the electrochemical method:}

The constant potential method is used to prepare Polypyrrole films electrochemically. All the films were prepared in aqueous media, at a constant potential of $800 \mathrm{mV}$. With the help of EA 162 Potentiostate. Initially, concentrations of dopants varied from $0.01 \mathrm{M}$ to $0.2 \mathrm{M}$, etc. to optimize the product. For most of the films, the concentration of $0.1 \mathrm{M}$ was found useful and the polymerization voltage was kept as $0.8 \mathrm{~V}$. Specially designed one compartment cell of $50 \mathrm{ml}$ capacity was used for electropolymerization Fig. 2 . The working electrode (WE) is made up of stainless steel plate (SS) of the size $5.5 \mathrm{~cm} \times 2.5 \mathrm{~cm}$. A platinum electrode was used as a counter (Auxiliary) electrode and a standard calomel electrode was used as reference (SCE). The Polypyrrole thus polymerized was found to have grown on both sides of the working electrode. During polymerization, some parameters like dopants concentrations and time ( 2 to 15 minutes) for polarization were varied.

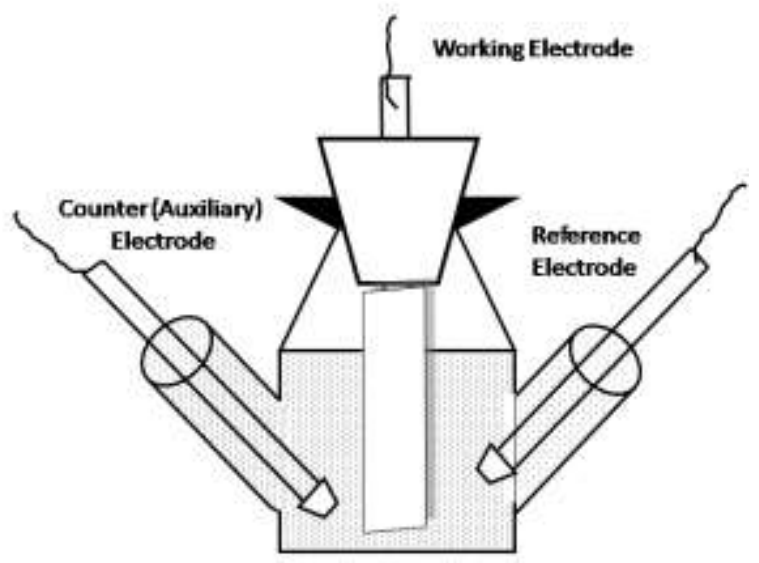

Fig. 1 Electro polymerization cell

\section{Characterization of Ppy films:}

\section{a Thickness:}

The thicknesses of all these films were measured by Dektak 150 Surface Profiler of Bruker Corporation and it was found that they varied from 5 to 25 microns. 


\section{International Journal of Current Science Research and Review}

ISSN: 2581-8341

Volume 04 Issue 07 July 2021

DOI: 10.47191/ijcsrr/V4-i7-07, Impact Factor: 5.825

IJCSRR@ 2021

www.ijcsrr.org

\section{b FTIR Spectroscopy:}

The chemical bonding was analyzed using FTIR spectroscopy. IR spectra of Polypyrrole doped with p-TS are shown in Fig. 3. One can very easily see the typical absorption bands at 3400,1400,1050, and $840 \mathrm{~cm}^{-1}$. There are supposed to be absorption bands corresponding to at $3400 \mathrm{~cm}-1$ for $\mathrm{N}-\mathrm{H}$ stretching and at $2940 \mathrm{~cm}^{-1}$ corresponding to $\mathrm{CH}$ respectively. These bands sometimes do not get resolved properly. However, the bands at 1400, 1050, and $840 \mathrm{~cm}^{-1}$ could be easily seen in most of the spectra. These are the characteristic bands of Polypyrrole. The absorption peak at (1636) $1700 \mathrm{~cm}^{-1}$ represents the presence of the carbonyl group which is present in the film. The band at $1540 \mathrm{~cm}^{-1}$ is due to ring vibrations of Polypyrrole, band at $1480 / 1430 \mathrm{~cm}^{-1}$ is due to $\mathrm{C}=\mathrm{C}$ and $\mathrm{C}-\mathrm{N}$ vibrations, band at $1150 \mathrm{~cm}^{-1}$ due to in-plane deformation, and at $1080,1020 \mathrm{~cm}^{-1}$ due to in-plane vibrations confirming the formation of Polypyrrole. The broad strong bands between $3440-3424 \mathrm{~cm}-1$ corresponds to the stretching vibrations of the intramolecular hydrogen bond $(v \mathrm{O}-\mathrm{H})$ and this frequency also shows the absorption of $\mathrm{N}-\mathrm{H}$ stretching of Polypyrrole. The frequency at $2916 \mathrm{~cm}-$ 1 refers to the stretching vibration of the $\mathrm{C}-\mathrm{H}$ bond. The absorption at $1636 \mathrm{~cm}-1$ was assigned to the $\mathrm{C}=\mathrm{C}$ ring stretching of pyrrole. The band at $1380 \mathrm{~cm}-1$ represents $\mathrm{C}-\mathrm{H}$ vibrations. The 1260 and $1189 \mathrm{~cm}-1$ are the peaks of stretched $\mathrm{C}=\mathrm{C}$ and $\mathrm{C}-\mathrm{C}$. The peak around $1040 \mathrm{~cm}-1$ corresponds to the in-plane deformation of the $\mathrm{O}-\mathrm{H}$ group and $\mathrm{C}-\mathrm{O}$ symmetric stretching. The $800 \mathrm{~cm}-1 \mathrm{band}$ is of in-plane deformation of the $\mathrm{C}-\mathrm{H}$ and $\mathrm{N}-\mathrm{H}$ bond of the pyrrole ring. The band at 687 is due to the $\mathrm{C}-\mathrm{N}$ bond. To determine the mode of bonding, we used the bands at $799 \mathrm{~cm}-1$ and $901 \mathrm{~cm}-1$.

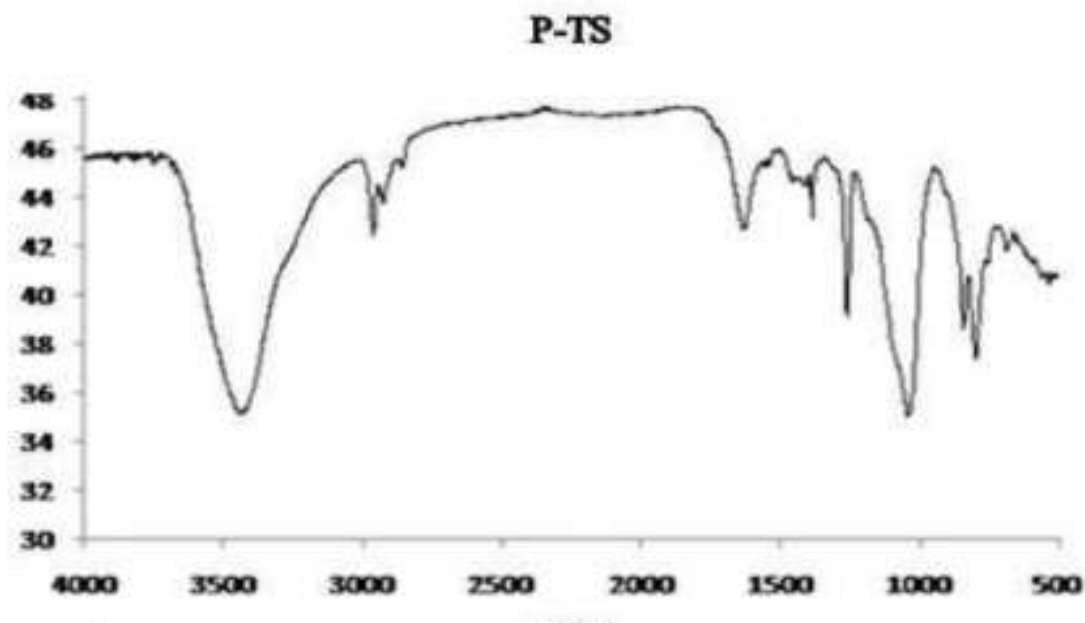

Fig. 2 FTIR spectrum of Polypyrrole doped with p-TS

\section{c. Morphology:}

The surface morphology of the film was investigated using SEM. The morphological features are depicted in Fig. 4. The larger globules show a Cauli-flower-like structure having smaller globules within it.

The sizes of the smaller globules varied between $0.2 \mathrm{~mm}$ to $2 \mu \mathrm{m}$ and the average globule size is $0.55 \mu \mathrm{m}$. The size varies between 30 to $50 \mu \mathrm{m}$. A few fully grown separated globules could be seen, but others were coalescing over each other.

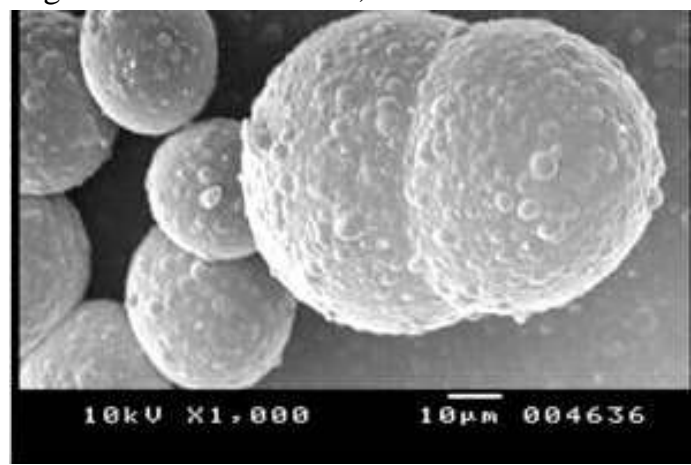

Fig. 3.SEM of Polypyrrole prepared by electrochemical method 


\section{International Journal of Current Science Research and Review}

ISSN: 2581-8341

Volume 04 Issue 07 July 2021

DOI: 10.47191/ijcsrr/V4-i7-07, Impact Factor: 5.825

IJCSRR@ 2021

www.ijcsrr.org

\section{c. Conductivity:}

Typical plots of I vs. V for Polypyrrole prepared by the electrochemical method for various thicknesses of films are given in Fig.5. Nearly linear relationship of the I - V curve was noted. The conductivities were found in the range of $0.05910-3 \mathrm{~S} / \mathrm{cm}$ to $11.87 \times 10-2 \mathrm{~S} / \mathrm{cm}$ for the thickness of the film increase from 0.475 to $\mu \mathrm{m} 22.265 \mu \mathrm{m}$.

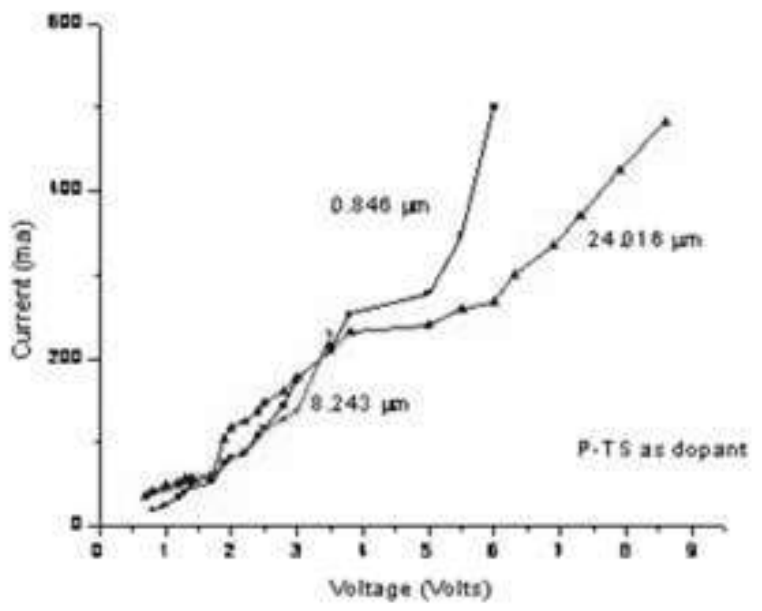

Fig. 4. Conductivity graph of Ppy

\section{UV-INDUCED RADICAL POLYMERIZATION:}

This method is based on oxidative synthesis under mild conditions where hydrogen peroxides as the oxidants, which carry out polymerization of the corresponding conducting polymer. Alternatively, the formation of Ppy particles of different sizes is possible by the variation of the duration of the polymerization reaction. Such Ppy particles, as well as particles of other conducting polymers, have attracted considerable attention in recent years because of their potential applications in various areas, such as drug delivery, electrochemical sensors, etc. To prepare pure Ppy, the $\mathrm{H}_{2} \mathrm{O}_{2}$ could be a very suitable oxidant for the synthesis of Ppy. The $\mathrm{H}_{2} \mathrm{O}_{2}$ can be easily removed from the formed polymer since it is not charged and does not form any ionic interactions within a highly ionized Ppy matrix, as is the case with ionic oxidants. Moreover, the unreacted $\mathrm{H}_{2} \mathrm{O}_{2}$ degrades relatively quickly to $\mathrm{H}_{2} \mathrm{O}$ and $\mathrm{O}_{2}$. The aim of the present study is the preparation of Ppy by oxidative $\mathrm{H}_{2} \mathrm{O}_{2}$ initiated polymerization. A very simple, environmentally friendly, one-step oxidative polymerization route to fabricate Polypyrrole (Ppy) of fixed size and morphology was developed and investigated. The herein proposed method is based on the application of hydrogen peroxide as a weak oxidant as a polymerization initiator. The polymerization reaction is performed for a $5 \mathrm{hr}$ time scale under standard conditions. Alternatively, the formation of Ppy particles of different sizes is possible by the variation of the duration of the polymerization reaction and changing the monomer to oxidant ratio.

\section{METHODOLOGY:}

\section{Preparations:}

For UV-photo processing, a precursor was prepared by using pyrrole and $1 \mathrm{M} \mathrm{H}_{2} \mathrm{O}_{2}$ in the ratio of 1:1. The solutions were mixed by stirring for $5 \mathrm{~min}$. The mixture was then poured into optically flat patry dishes in which pieces of Glass plate, Polyester film, and Copper foil of size 1 square $\mathrm{cm}$ each were kept dipped in the solution. The solution was then exposed to UV radiation from a UV lamp (wavelength of $200 \mathrm{~nm}$ ) for $5 \mathrm{hrs}$. The distance between the sample and lamp was $15 \mathrm{~cm}$, with the lamp having $125 \mathrm{~W}$ of power. At the highest power densities applied, the sample surface temperature did not rise above 700C. The thin film of Polypyrrole started depositing on various substrates after nearly 1 hour and the sufficiently thick film was formed after 5 hours. The substrates were then taken out and washed thoroughly with distilled water several times. The films were dried for 1 day and used for testing. 


\section{International Journal of Current Science Research and Review}

ISSN: 2581-8341

Volume 04 Issue 07 July 2021

DOI: 10.47191/ijcsrr/V4-i7-07, Impact Factor: 5.825

IJCSRR@ 2021

www.ijesrr.org

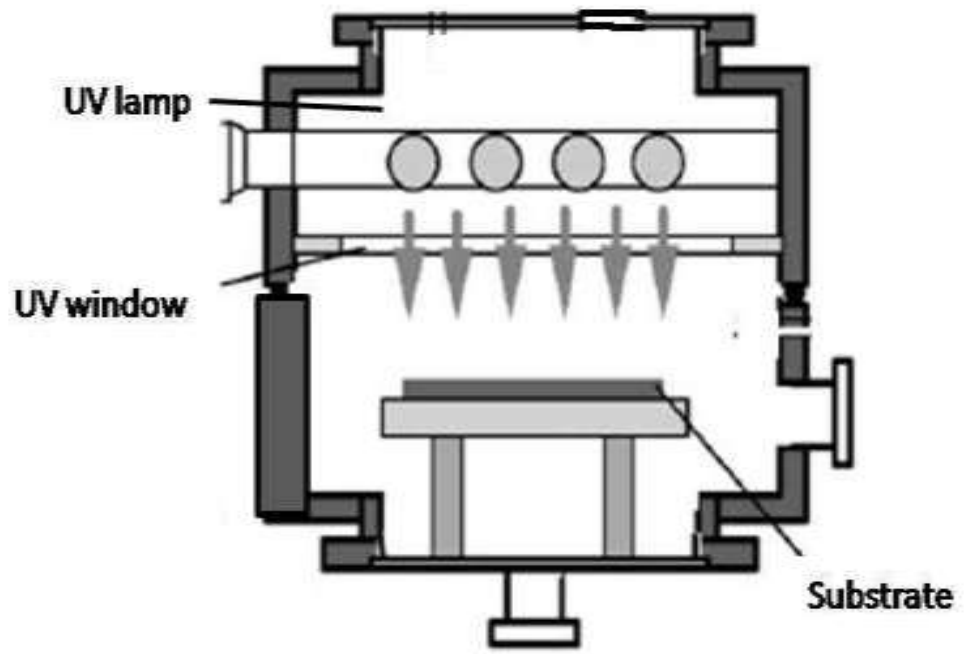

Fig. 5. UV chamber for photo processing of pyrrole

\section{Characterizations:}

\section{i. FTIR Spectroscopy:}

FTIR shows a broad absorption band between 3400 and $3000 \mathrm{~cm}^{-1}$ corresponding to $\mathrm{NH}$ stretching (NH), aromatic $\mathrm{CH}$ stretching $(\mathrm{CH})$, and free-carrier absorbance in the doped Ppy. The region below $1700 \mathrm{~cm}^{-1}$ shows characteristic Ppy bands. The bands due to $\mathrm{NH}$ stretching $(\mathrm{NH})$

$\left(3400 \mathrm{~cm}^{-1}\right)$, aromatic $\left(3100 \mathrm{~cm}^{-1}\right)$ and aliphatic $\left(3000-2800 \mathrm{~cm}^{-1}\right) \mathrm{CH}$ stretching $(\mathrm{CH})$ which are present in the doped Ppy. It is noted that there are weaker peaks in the case of UV irradiation. This is due to the microstructural changes by UV-photo processing. A hump at 780 shows that the mode of bonding is pre dominatingly $\alpha-\alpha^{\prime}(2,5$ linkages $)$

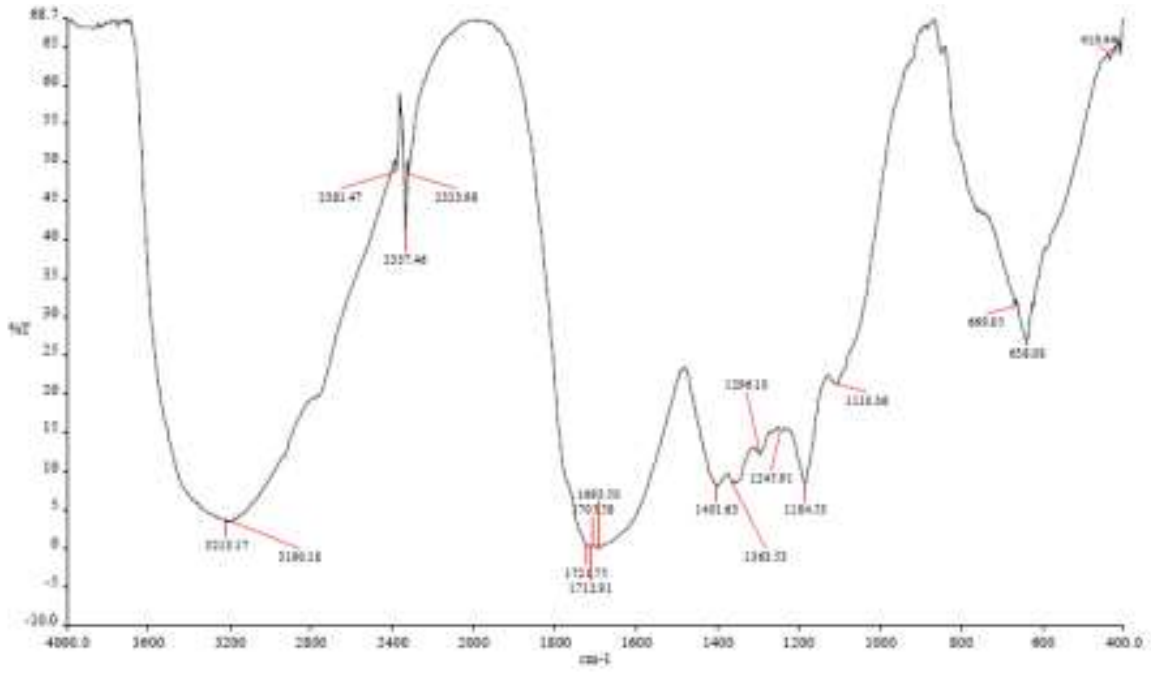

Fig.6. FTIR of Ppy + H2O2 1:1 5Hr. UV Radiation

\section{ii. SEM of Ppy films}

The SEM of Ppy films prepared by UV-processing is shown in Fig. 7. (It is well evidenced that UV-photo processing of Ppy film consists of two stages: first; photo-polymerization; then Ppy film surface etching and modification under a UV-radiation). The morphology does not resemble globular nature as seen in electrochemical polymerization routes. Rather we find some granular structures over a planer plate surface. The size of the grain varies from $0.22 \mu \mathrm{m}$ to $0.54 \mu \mathrm{m}$. The average size of the grain is $0.381 \mu \mathrm{m}$. 


\section{International Journal of Current Science Research and Review}

ISSN: 2581-8341

Volume 04 Issue 07 July 2021

DOI: 10.47191/ijcsrr/V4-i7-07, Impact Factor: 5.825

IJCSRR@ 2021

www.ijcsrr.org

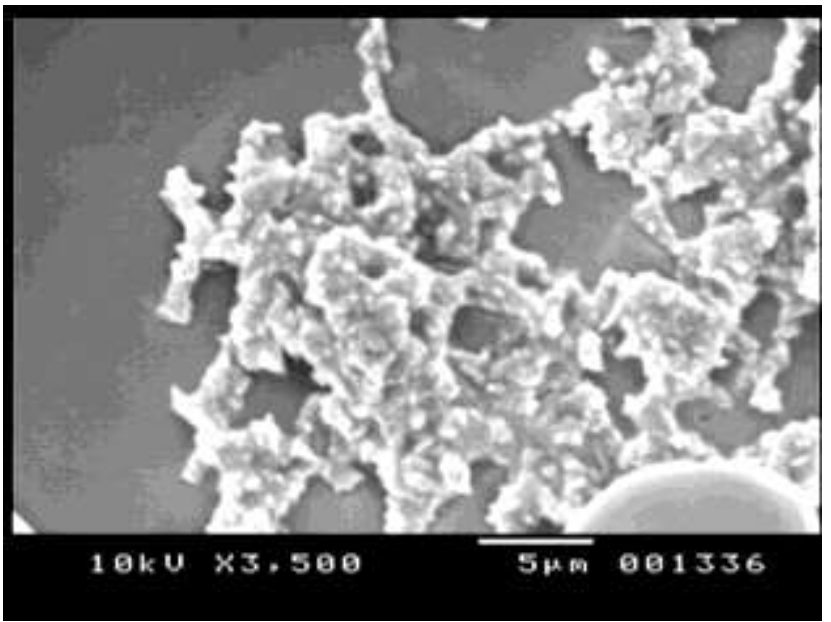

Fig. 7. SEM of Ppy prepared by UV photo irradiation

\section{iii. I -V Characteristics:}

The conductivity of the PPy powder prepared by UV photo-irradiation was tested by two probe methods by preparing its pellet of the surface area of $1 \mathrm{sq}$. $\mathrm{cm}$. The graph shows that the sample is not a good conductor of electricity. The current is of the order of a few $\mu$ A. This may be because the polymerization may not be giving a long chain and therefore the film was brown

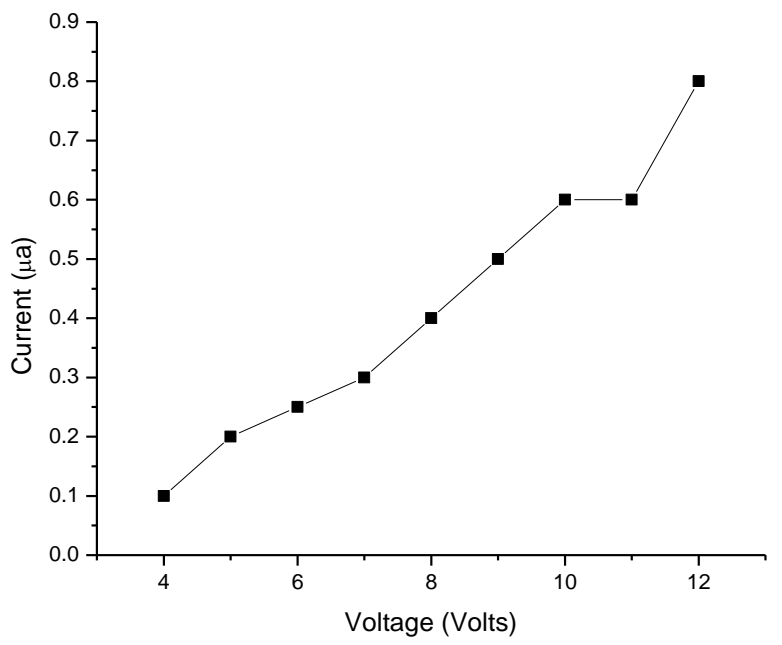

Fig. 8 I vs V graph for UV photo Polymerization of Ppy

\section{CONCLUSION}

Polymerization of pyrrole using Electrochemical and UV Photo irradiation has been investigated. The main purpose was to study the mechanisms involved in each method and evaluate the advantages of each method. Like the Electrochemical method gives Ppy in film form and the conductivity is very good. The morphology of Polypyrrole prepared by the electrochemical method showed globular nature.

Ppy by UV Photo irradiation is a very simple, environmentally friendly, one-step oxidative polymerization route to fabricate Polypyrrole (Ppy) based on the application of hydrogen peroxide as a weak oxidant as a polymerization initiator, which avoids the problem of toxic materials (due to oxidants). 


\section{International Journal of Current Science Research and Review}

ISSN: 2581-8341

Volume 04 Issue 07 July 2021

DOI: 10.47191/ijcsrr/V4-i7-07, Impact Factor: 5.825

IJCSRR@ 2021

Www.ijcsrr.org

\section{REFERENCES}

1. Q. Fang, D. G. Chetwynd, J. W. Gardner, "Conducting polymer films by UV - Photo Processing, Sensors and Actuators A Vol. 99, 2002, pp. 74-77

2. M. R. Karim, C. J. Lee, M. S. Lee, "Synthesis of conducting polypyrrole by radiolysis polymerization method", Polymers for Advanced Technologies, Vol, 18, 2007, pp. 916-920

3. J. Unsworth, A. Kaynak, B. A. Lunn, and G. E. Beard, "Microwave transmission, reflection and dielectric properties of conducting and semiconducting polypyrrole films and powders", Journal of Material Science,Volume 28, Number 12, 3307-3312

4. 4 He, J.; Gelling, V. J.; Tallman, D. E.; Bierwagen, G. P.; Wallace, G. G., Conducting polymers and corrosion III. A scanning vibrating electrode study of poly(3-octyl pyrrole) on steel and aluminum. Journal of the Electrochemical Society 2000, 147, (10), 3667-3672.

5. KarolisLeonavicius, Almira Ramanaviciene and ArunasRamanavicius, Polymerization Model for Hydrogen Peroxide Initiated Synthesis of Polypyrrole Nanoparticles, American Chemical Society, Article in press

6. Q. Fang, D.G. Chetwynd, J.W. Gardner, Conducting polymer films by UV-photo processing, Sensors, and Actuators A 99 (2002) 74-77

7. V. Brandl, R. Holze, Ber. Bunsenges. Phys. Chem. 102 (1998) 1032.

8. A. Angeli, Gazz. Chem. Ital., 46, 279 (1916)

9. A. Angeli, L. Alessandri, Gazz, . Chem. Ital., 46, 283 (1916)

10. G. P. Giardini, Adv. Heterocyclic Chem. Chem., 15, 67 (1973)

11. K. K. Kanazawa, A. F. Diaz, W. D. Gill, P. M. Grant, G. B. Street, G. P. Giardini, J. F. Kwak, Synth. Met., 1, 329 (1980)

12. K. K. Kanazawa, A. F. Diaz, G. P. Gardini, J. F. Kwak, JCS Chem. Commun., 635 (1975)

13. K. K. Kanazawa, A. F. Diaz, R. H. Geidd, W. D. Gill, J. A. Logan, J. F. Robot, G. B. Street, G. P. Giardini, J. F. Kwak, JCS Chem. Commun., 854 (1979)

Cite this Article: Dr. Hemant K. Chitte, Dr. Shraddha M. Bhome (2021). Study on Comparative Analysis of Polymerization of Pyrrole Using Electrochemical Method and UV Photo Irradiation. International Journal of Current Science Research and Review, 4(7), 660-666 